\title{
NABOKOV'S CODE IN THE EARLY WORKS BY L. ULITSKAYA: LITERARY CRITICISM AND TRANSLATION ASPECTS
}

\author{
Prof. Natalya Kovtun ${ }^{1}$ \\ Prof. Veronica Razumovskaya ${ }^{2}$ \\ ${ }^{1}$ Krasnoyarsk State Pedagogical University named after V.P. Astafyev, Russia \\ ${ }^{2}$ Siberian Federal University, Russia
}

\begin{abstract}
In modern criticism, V. Nabokov is revered as one of postmodernism "godfathers". In the texts of a number of iconic contemporary writers (from A. Bitov up to $\mathrm{O}$. Slavnikova and L. Ulitskaya) the influence of "Lolita" author's creative works is highly significant. L. Ulitskaya never attributed herself to the postmodernist trend; on the contrary, she insisted that aesthetics under the sign "post" is becoming obsolete. Such experience of the author's self-identification beyond the post-modernism's aesthetics is worth to the literature at the turn of the 20th century. Ulitskaya point out $-\mathrm{V}$. Nabokov's prose, in her comprehension, is an ideal one, an appeal to the writer's image and to his characters proves the scale of an individual artistic concept. The problem of intertextuality links between Ulitskaya's works and Nabokov's prose has been addressed by the critics. Among others, the attention has been paid to the tale "Sonechka" [1] and such stories as "Bron'ka" and "Golubchik" (eng. - "Dear Fellow") [2], thought the earlier texts of the modern author as a single metatext where Nabokov's influence can be identified at the level of literary devices, images and author's philosophy have not been considered under this context. In Ulitskaya's Hall of Fame of the Russian literary geniuses the name of Nabokov comes right after Pushkin. In the collection "The Holy Garbage" Ulitskaya highlights the key points in a perfectly precise way: "Nabokov... has set the national literature free from that typical flavor of unhealthy religiousness, groundless messiahship, hysteria-accented social worries, feeling of a permanent guilt mixed with teach-shadowing and created almost a crystalclear, sheer "higher" literature with a non-traditional degree of the author's estrangement from the text" [3]. Thus, the most crucial part among the writer's literary heritage is the didactics poverty, estranged attitude towards his characters and a special status of the artistic word, the rhythm and melody of which discover new possibilities of the modern literature and express those previously unnamed things.
\end{abstract}

\section{INTRODUCTION}

The first meeting which determined the authoress inner development was the novel "Invitation to a Beheading" which vividly influenced one of her best stories "Sonechka" [4]. The images of Nabokov himself and his characters can be recognized through the characters. The definiteness of the protagonist's - Robert Viktorovich - fate is proved by the references to Nabokov and resembles a "line broken as the moth's flight" [5]. The character's image hides some features of the Russian writers and artists. A recent prisoner set for a penal settlement, "a man from underground", meets Sonechka, a librarian (a paraphrase of Sophia/Wisdom), finds his family and ground. The reference to a well-known austerity of the characters and their interest in reading make a parallel with Sonechka Marmeladova and Raskolnikov more actual, however, 
instead of the Bible, these two lovers are drawn together by the French literature. Against the backdrop of a tranquil and infantile Sonechka wrapped up into novels, being deaf to the borders between the reality and texts, that freethinking of her beloved, being devoid of any common truth, becomes more noticeable. Missing any shine of intelligence, the heroine, however, is a good listener - she manages to keep everything said and created by the master in her mind. These two characters' unity represents an ironic remark towards the interrelations between L. Tolstoy and his wife as it is described in "The Holy Garbage" by L. Ulitskaya (2012).

\section{MATERIALS AND METHODS}

The comparative and descriptive methods were mostly used to obtain relatively reliable and convincing results in the present research. Ulitskaya's literary discourse was studied with a help of motif method.

\section{RESULTS}

The paper models of "mysterious things" and "fiction cities" created by Robert Viktorovich are accompanied by the signs of "cabalistic alphabet" that plays upon the famous experience of V. Soloviev interested in Neo-Platonism, Cabala and magic. The text emphasizes the foreignness of the master's cities, the historic Moscow "by no means was like either Athens or Jerusalem to him", though the meaning of these sights is a secret even for the inner circle. Thus, the story declares the motive of Nabokov's interest in charades, which is principal for Ulitskaya's texts in general. Unfailing readiness to ordeals and unexpected twists of fate are close to the trickster's nature. The character's space interweaves the lines of the hero-demiurge and his twin, i.e. a jester and player. Robert Viktorovich's artistic experiments are farcical reflection of the human history. Playing tricks of the protagonist are recognized in the history, the paper compositions form the core of a new artistic genre - "paper architecture"; "bold plays with the space taking apart and pulling out" yield the fame of a designer marked by the fate of Cincinnatus. The play power also establishes the reading preferences of the character as against his wife, a classic admirer; "he was absolutely indifferent to the Russian literature, finding it to be bare, tendentious and moral beyond all bearing". In "The Hole Garbage" the same feature is almost literally referred to Nabokov's image. Pushing away from a mundane capital life bricked in a fear, the artist creates his own world-theatre that no one, no Karabas-Barabas - Stalin - is able to take. The thing that could never be reached through the official ways, comes "out of the blue" as the result of a genius maneuver, a trick. The features of Nobokov's Lolita are also can be seen images of the protagonist's daughter and his lover Yasya. We can guess behind the image of the artist the figures of avant-garde masters - R. Falk and K. Malevich. Robert Viktorovich's fate mirrors Falk's highlights; a contiguity between the images evidenced by a common nationality and names match. The experiments with white colour, the mystery of inexpressible, the cosmos's inner melody addressed by Malevich is found in a series of "white portraits" by Robert Viktorovich. In the light of formalism aesthetics, the protagonist's coldness towards the Russian literature is featured by a new tone - the culture of avant-garde "is especially implacable to the literacy and words. In paining the fight against words is addressed by Kandinsky and Malevich" [6]. The artist's desire to embody the sacred nature of things - wisdom - brings his techniques together with the icon-painting devices. 
The final series of the master including 52 paintings is associated with a pack of cards, which, according to the legend, are tied to the secret wisdom of the Knights of the Temple (Tarot cards means "the King's way to the wisdom") and to a labyrinth as a symbol of illusive earthly life. The scene of the protagonist's funeral is described in the same playing stylistics, combines the elements of a stage production and ritual referring to Cincinnatus's execution will be continued in "Funeral Party" (1992 - 1997). The pall is surrounded by the paintings. The people were different - they were hurry in expectation of a show. The motives of mirrors, stage and curtains are intertwisted with the images of a devotional concentration, dropped curtains, silence and died out candle. The dead is portrayed once in the image of a grand master taking a sudden move, or as Nabokov's Luzhin, or as Jacob from the Bible, a forefather of the "great people" (Gen.35:14). The story shows a symbolic closeness between three women, each love of whom resembles three lives of Robert Viktorovich, whose portraits he draws. Sonechka, who saved the character from the "limbo", gets her portrait as a wedding present. Then, it is the turn of Tanya, his daughter, the birth of whom wakens the game/creation spirit in her father. Finally, before the Eastern holiday the master discovers the beauty of the white as being in the basis of the world, and paints Yasya: "It was not a work of the model. It was as if he drunk her and now only glanced into his secrecy" (53). Robert Viktorovich as well as Humbert Humbert creates Lolita's image in his own mind. The portraits reveal in that earthly woman a uniqueness of the prototype, a dream about the Paradise, what, according to Ulitskaya, has been marked by Nabokov's literary works.

The system of characters in the story is organized by the relation to play/creation; it makes us remember "Invitation to a Beheading" involving the directors/demiurges and their obedient hand puppets. The main plot plays also with the Pygmalion "complex" represented in V. Soloviev's philosophy. The savers of the Beauty are played by mythical characters: Pygmalion symbolizes the beauty (Galatea), Perseus and Orpheus rescue her from the universal evil (the stories of Andromeda and Eurydice). The female version of the master/director is shown by the image of Robert Viktorovich's daughter, by his clone - Tanya. Similar to her father, Tanya has been surrounded by that air of freedom from the childhood; the girl grows up as a short person, bold and noisy, that does not comply with that period of time. The woman's image is marked by the elements of iconography. Even the ordinary medium, the things in Tanya's room are described with unique features and sounds; her piano/barrel organ reveal the "secret of the thing's nature" associated, in Ulitskaya's world, with Nabokov's talent. While, to self-realize Robert Viktorovich needs canvases and paper..., Tanya plays with the sounds, experiments with her body. While Tanya was asked from the hand of God, her mistress, Yasya, a derivative of "The Glass Bead Game", is a personified illusion. The images of her friends form a twin-couple, that is proved at the all levels of the text: from the attributes, favor choices to an allusive relationship. The motive of Cybele's "red tongue" joking on Robert Viktorovich the day before his wedding, is echoed in the images of little socks of "red wool" in Tanay's plot line (similar to Hermes), and of a "red fabric handbag" - in Yasya's one. In the same war Perseus comes for Gorgon's head with the mystery hidden inside. This plot is a clue to Nabokov's novel "Ultima Thule" important for the whole Ulitskaya's work.

As once the mind and quick reaction peculiar to Robert Viktorovich are enhanced in the dialogs with his wife, as Tanya's self-conscious is expressed though her monologues addressed towards her friend. Blurred image of Yasya, as well as Nabokov's Lolita, its 
puppet nature has been highlighted more than one time. The love triangle: Robert Viktorovich, Yasya and Sonechka, is flashed by the character of a famous novel: Humbert Humbert, Lolita and her mother. in that way, as well as Nabokov's character, Robert Viktorovich dreams on revealing the secret of the First Creation, of the Paradise in his love with Yasya. The elements of Gorgon's image are evident in Tanya's and Yasya's portraits. It is worth to note that in all the variants of twin-couples in Ulitskaya's works the role of a travesty twin has greater importance. The rescue of Sophia's poor souls, a drawn "pearl", made by the artist lies in the relations between Robert Viktorovich and Yasya. The girl moves behind the curtains of her life from one gooddoer to another. Her vamp behavior is characterized by deliberateness, platitude and naiveté emphasized by the comparison with Marphinka from "Invitation to a Beheading". The "transparency" of Yasya's appearance accompanies the puppet environment of Cincinnatus. At the character's level such farcical situation gets the sense beyond the reach of the hand-puppets. The moment of their first affair strikes, as in Humbert, by his childhood memories.

A duo of Tanya and Yasya is marked by the images of Tatyana Larina and Asya Turgeneva reasoned by their names play and the portrait details. The nature of Asya who dreams about looking like Pushkin's Tatyana and keeps silent about her real mother's fate, are seen in the features of both heroines. Deciding to conquer the capital, Yasya makes ablution/christening in the WC of the Kazansky railway station. The residence in Moscow does not, however, go beyond the curtains, the grotesque "bottom"; she washed floors in a school/labyrinths and "muddy toilets". The entrance into Sonechka's family has quite a pragmatic aim, i.e. to improve her own position, winning the support from other good-doers. The heroine's self-consciousness, awaking of femininity inside her are promised by the meeting with the artist who leads a vagabond soul/puppet from the world of reflections - from the labyrinth. The image of Yasya, as well as Lolita's one, is surrounded by a bestiary, i.e. is created through hushing sounds: she speaks "lisping whisper", washes "rough school corridors", accompanied by the "swish of a raffish silk", "rash of sweets wrappings". Lolita, a young vamp-girl, is born right in Humbert Humbert's mind that has almost nothing with the story of a real girl in Ulitskaya's work, vice versa, Yasya's biography turns out to be vicious and her transformation is expected after her meeting with the master/director. Her favorite hobby before this event was to lie "curling into a ball" near Tanya "sitting in the lotus pose" and making "wrong music of the flute". One can observe an ordinary picture showing a magician charming a snake. The motive of the snake basket - an allegory of woman - is a cross-cutting idea in Ulitskaya's literary works. While meeting his daughter's friend, the protagonist feels himself as being "bitten"; the young girl stay for the night in a "corner room" folded by the early twilights. The motives of edge, corner and triangle lead this image.

The porcelain-like whiteness of the face and shoulders of matured Yasya, a "small steep brilliant on the finger", the atmosphere of hushing sounds refers to the character of Helen in "War and Peace" by L. Tolstoy. Robert Viktorovich, however, sees in his beloved a young Natasha Rostova. The metamorphose also concerns the master's interests in literature - at the story's outset that Russian genius is Pushkin, in the end - a didactive L. Tolstoy preferred by Sonechka. Love towards Yasya makes the wiseman closer to his naive wife. After Robert Viktorovich's death the life of his beloved enters an ordinary course; the girl finds her relatives in Poland who will appear later "like a 
jack in the box". It is interesting that Yasya's depravity per se turns out to be a perspective one for the heroine's environment. Robert Viktorovich and Tanya owe to Yasya for the performance of their own ego, for the escaping from a domestic captivity/labyrinth. That confided love affairs between her father and friend forces Tanya to start travelling; she learns languages (another link to Nabokov's experience), becomes an employee in the UN and literally actualizes the "wisdom" function of psychopomp. She stays at Switzerland, where Prince Myshkin stroke by the meeting with Nastasya Filippovna (as with Gorgon) finds his home.

Among other great texts written by Nabokov, Ulitskaya points out the novel "The Gift". The collection "The Holy Garbage" contains a specially dedicated story "Reading Vladimir Nabokov's "The Gift'". The most important theme in this novel, as the authoress sees it, is a vagabond concept, i.e. emigration/banishment and homesick referring to Homer. Ulitskaya concerns "The Odyssey" as a sacral text reflecting the human history. The parallel with the poem (though Nabokov's and deeply respected J. Joyce media) is depicted in the novel "Medea and Her Children" (1996). As well as "The Gift", Ulitskaya's text says about the mystery if writing, about the search for an internal word addressed to the reader who is able to comprehend that sophisticated game. The novel is an "encyclopedia" of artistic methods, principles of discourse creation, starting from the Ancient times till the Post-Modern Era. The characters' images can be quotable, they possess certain features of well-known heroes and the portraits of prominent writers considered as the creators of a single text of the culture. The text per se represents Ulitskaya's ironic and delicate request on being included into the elite. The authoress also pays extra attention to the harmony of artistic methods: in "The Gift" one can find a balanced combination of the scientific knowledge about the world together with a fiction or with an artistic game. It is no mere chance that Nabokov wanted to published the text with additional parts, one of those would be titled as "Father's Butterflies". Ulitskaya assumes that such combination of the scientific and creative approaches to the world view comprehension proved to be successful by U. Eco who dealt with Nabokov's plots in his own works.

In Ulitskaya's novel the exposition is built on the history of Synoply dynasty rooted in the ancient time; the conclusion, in turn, contains a call for entering the world artistic community - Medea's family, for what one should be gifted by hermeneutics, an ability to self-reflection, despite the leading ideologemes of the Soviet power. The text is the author's revision on herself and her experience, thus, there is such an abundance in selfcitations. The truth's tracks are guessed by Ulitskaya within the private life, "beyond the time", and only in that way - from the inside of one's home/spirit - the universe picture can be revealed. The motion within the artistic space is supported by the description of "spirit ordeals"; the text is rich in mythological motives about the afterlife trips, allusions to the Bible, Dante, in the depiction of dreams and visions. At the same time, the common plots are transcribed by the characters; their positions become different; the author builds a gallery of scenes and pictures resembling the cinema art. The process of free "assuming" of the canonical texts add an extra significance and individuality. The image of the protagonist - Medea - hides the figure of a "smart Odysseus". She even feel herself "not less than as Odysseus" who "was searching for the adventurous and who was the Man of the Water, and he never missed his chance to postpone his return, more pretending that his goal is a rough house in Ithaca" [7]. In this interpretation the ancient hero enjoys the trip/creation, searches for the Promised Lands as unwritten texts. 
The description of Medea's country-seat has vivid features of a pyramid and Dante's Purgatory. Near the root of the canonical mountain there is a well filled with "precious water"; on the top - there is a toilet with the sign "Leaving, look back - is your conscience clear?". The climb symbolizes the process of initiation, i.e. within this place everyone has to learn about love, friendship, cheating - their own Paradise and Hell. On the top of the mountain Dante meets Beatrice, the poet - his muse; this plot has been reconstructed in the stories of the characters. Still, the only image of Medea has been put beyond the framework of human games and compared with the narrator's prototype.

The heroine is a picture of the world tree surrounded by the genesis. She is "a part of the landscape", the keeper of a wisdom hidden in the earth per se as in a book; a sole who knows "near to the Greek language" which involves "an amazing literacy and initial sense of the words". In the texts of the Enlightenment period the ancient Greek and Latin are perceived as the languages of the Dedicavit; they are applied to in the case of searching for the Promised Land. The secret kept behind the line of letters, signs is that very "Golden Fleece" and the modern reader is welcomed to find it. A black and tall Medea, calling herself as "Devil's rake" is a personified stylus, the well - an inkpot. Medea's children are artists who design the world. The key to the home/temple the Mistress keeps under a "triangle stone" referring us to the most important masonic symbols - Cyclops's third eye, i.e. to the center of the human spirit. Medea's house situated "in the very center of the Earth", "in its belly-button" combines the features of Colchis, Ark and Calvary; however, in the relation to the modern civilization such position of a "humble stage yard for the history" is marked just by case. The coffer belonging to Medea hides the human destinies. As well as Nabokov, she loves to solve the human histories similar to charades. She is characterized by audacity, inner freedom even in the context of the Soviet regime, by the ability to dispute with the Gods as well as that smart Odysseus. Her involvement into the world creation secrets excludes Medea of the range of instant ideas on the good, the evil and the truth. L. Ulitskaya at the same time characterizes her heroine with the features of an ascetic and infernal marks.

Apart from Medea's image which organizes the tax, Nabokov can be also traced through the history of her granddaughter - a novice poetess Masha. The girl's name is linked to Nabokov's "Mashenka"; the image of the absent character embodies the former Russia, a country, from which the author was exiled forever. Masha's face is undeveloped, as if it were a "transfer picture", a decal of the photo of her mother, Tatyana (referring to Pushkin's heroine considered as the Russian woman image), the "reflection of reflected". The heroine accents on her childlishness, androgyny features and proclivity for the mystery. While Medea's fate is marked by the mythology of certain spaces, Masha's destiny is tied to "a bad place", the general's house - the territory of fear, lie and madness. This is not a place for living, but for an opportunity to go insane and to die. These borders should be underwent/overcome, as if you defeated your death: at night Masha meets a crazy general's wife, which functionally and attributively reminds about the Queen of Spades. In this "hell" the girl was perfectly conducted by the relatives and the Night Angel. From her childhood the heroine gets used to the help of "interpreters"; she even sleeps taking someone by the hand. Her relations with the husband is a travesty version of the myth on Orpheus and Eurydice and naturally "completed" Nabokov's plot - the husband is late to take Masha away from the Soviet country and she dies. The nightmares, inner insanity of this girl, her obsession to 
Butonov as an ideal character of the social realistic texts is a metaphorical rendering of the state's history which now is suffering the idea of communism.

The lack of completeness distinguishes Masha's poetry. It is known that Nabokov represented himself as a poet first, and Ulitskaya calls this point of his biography as "a delicate joke of his life", since his poems were "ordinary and boring" ("The Hole Garbage"). Masha's tragedy is in her extraordinary trust to the letter, linked to the image of Sonechka form the story of the same title, in the absence of that very rhythm which made, according to Ulitskaya, Nobokov's prose popular. An intellectual Masha is perceived by her relatives as a "teenager", as an object of another's will. Her love to Butonov is formed according to the rules of a "soup opera". The relationship between the characters are quotable; they include the versions of the myth on Narcissus, motives performed in "Eugene Onegin" and industrial novels of the social realism. Ulitskaya's heroine is a victim of an unfair interpretation of the discourse; she calls out to her romantic beloved, she believes in a "bright future", but in front of her there is a poster image of a "true man", of a superman from the mass literature.

In this novel the characters' fate is determined by their battle against the Soviet State/Leviathan; and the spirit wandering is the "fight with the Angel" referring to the plot by Jacob the Prophet as a clue to Ulitskaya's works in general [8]. Only the winners takes their own voice and home. The Angel comes to Medea who speaks to the God as "a mix of already grinded prays and her own voice, lively and thankful..." (169); and only Masha in her night flights with the Angel uses not her "intelligence power", but "the one given by the teacher". Finally, she, like the Soviet Russia, finds herself in a quarrel with the world and herself: "As if there were two of them: a daytime Masha, calm, tender and friendly, and a nighttime Masha - frightened and tired-out" (135). The girl's end represents a paraphrase to the idea of Nabokov's Luzhin who stepped from the present time over the eternity, who became inaccessible for the life and history. After Masha's death her relatives publish the collection of her poems. It is known, that by the same publishing Sirin begins the path for his talent.

The story "Funeral Party", the novel "Sincerely Yours, Shurik" relate to the mentioned Nabokov's work "ltima Thule" that can be analyzed as a material for the further research. The main characters, like Falter, are described as from Gorgon's head. Their fates also remind a move from the truth to truth which impress by their ordinary or even absurdity. The moment of insight cannot be identified - it reaches as Gorgon's look, and in this very moment one can "find and get all the parts of this sauce-boat, of this soupboat", the shatters of which are spilled over "a smoked seaside" and "completely repair the dish in the very first - and not any other one - morning" (V. Nabokov). The truths are everywhere, as the authoress assumes, they are vanished, absurd and can be picked up together only by a man who becomes the main truth. The man's birth and selfdevelopment is similar to the world creation suitable for living there only in the case of being blessed by the beauty, memory and love that bases the following truth. One man's life shadow impacts the memory, creation of other people; thus, one more truth is the art as a meta-shadow, as a higher game. The chain of such truths grounds the momentum of a person development and the world dynamics which is fragile and may well become empty if no one creates, throws the shadows/ornaments in the space.

Taking into consideration the theory of intertextuality and the relevant idea of "strong" texts we may assume that Nabokov's texts are considered to be the "strong" ones in 
relation to Ulitskaya's creativity. In this aspect the reader must not only decode her aesthetic message but also "recognize" and decode implying Nabokov's code. Being popular literary translation object (translated into more than 25 languages) Ulitskaya's texts present a certain challenge for the translators. And one of these challenges is evident Nabokov's code in Ulitskaya's text. Following Gadamer's idea that a translator is extremely attentive reader ("super-reader") [9] we realize that one of the important tasks for the translator is to "recognize" Nabokov's code in a source text by Ulitskaya, decode it and then to reconstruct it in a target text.

\section{CONCLUSONS}

The creative game played by Ulitskaya with her readers just lies in such great truths disclosure, in revealing the plots of the world classic which obtain new interpretations and can be "completed" giving a birth to other meaning that keeps in time. The author's game with the signs of other times is aimed at studying the possibility and return from the sign to the sense. The world's core in her works is the artist who wanders in the labyrinths of the world creation searching for the Beauty; his mistakes sometimes are as much fruitful as the discovers; the most important thing is one's inner experience, a skill to tell the stories. The reading then can be comprehended as the process of initiation and a trick at the same time; the reader, like a newcomer, searches their own exit from the cave/library towards the light. Having Ulitskaya's original texts and the secondary texts of interlingual translations (mostly English ones) the authors of the present article conclude that the Nabokov's code in Ulitskaya's original texts determine a specific strategies of its reconstruction in literary translation. Nabokov's code is considered to be a unit of translation conveying cultural and aesthetic information.

\section{REFERNCES}

[1] Larieva E., "There are Games I Do not Play". or "Do"? Nabokov's Intertext in the Story "Sonechka" by L.Ulitskaya, The Materials for the Dictionary of Plots and Motives in the Russian Literature. Novosibirsk, issue 8, pp. 222-235, 2009.

[2] Glazinskaya E., L.Ulitskaya's Lolita: Intertextual Ties with V.V. Nabokov, New Science: Current State and Perspectives, issues 11-12, pp. 98-100, 2016.

[3] Ulitskaya L., The Holy Garbage, Moscow, 2012.

[4] Kovtun N., The Destiny of the National Classics within the Intertextual Space of the Early Texts by L. Ulitskaya, Journal of Novosibirsk State University, vol.11/issue 2, pp. 172-179, 2012.

[5] Ulitskaya L., Sonechka: Stories and Tales, Moscow, p. 16, 2006.

[6] Paperny V., The Culture Two, Moscow, pp. 221-222, 1996.

[7] Ulitskaya L., Medea and Her Children, Moscow, p. 165, 2005.

[8] Kovtun N., Intertextual Play in L. Ulitskaya's Novel "Medea and Her Children", Respectus Philologicus, vol.12/issue 22, pp. 85-98, 2012.

[9] Gadamer H.-G., Wahrheit und Methode. Grundzüge einer philosophischen Hermeneutik, Tübingen, 1990. 